\title{
A case of Uhl anomaly treated with one and a half ventricle repair combined with partial right ventriculectomy in infancy
}

\author{
Shinpei Yoshii, MD, a Shoji Suzuki, MD, a Shigeru Hosaka, MD, ${ }^{a}$ Hiroshi Osawa, MD, ${ }^{a}$ Wataru Takahashi, MD, ${ }^{a}$ \\ Kohki Takizawa, MD, a Samuel J. K. Abraham, MD, ${ }^{\text {a } Y u s u k e ~ T a d a, ~ M D, ~}{ }^{a}$ Hisashi Sugiyama, MD, \\ Tetsushi Tan, MD, ${ }^{b}$ and Toshie Kadono, MD, ${ }^{\text {b }}$ Yamanashi, Japan
}

$\mathrm{U}$ hl anomaly ${ }^{1}$ is known as a rare entity with a poor prognosis. ${ }^{2}$ Few reports have been published on surgical treatment, ${ }^{3,4}$ especially in infancy. We report our experience with the surgical treatment of an infant with Uhl anomaly who underwent the bidirectional Glenn shunt, namely, one and a half ventricle repair, combined with partial right ventriculectomy.

\section{Clinical Summary}

A 2-month-old boy was admitted to our hospital with poor weight gain, cyanosis, and tachypnea. Uhl anomaly associated with an atrial septal defect as the right-to-left shunting lesion was diagnosed. Investigation by echocardiography, cardiac catheterization, and magnetic resonance imaging demonstrated that the right ventricle was markedly enlarged and its wall was extraordinarily thin and hypokinetic. The electrocardiogram showed $\varepsilon$ wave. After initial medical treatment for 2 months, the patient was able to leave the hospital. However, he was readmitted in 8 months because of severe right-sided heart failure. On close examination, both the right ventricle and the right atrium were massively enlarged, which caused moderate tricuspid regurgitation. The atrial septal defect was almost closed, and the left ventricle was small and flattened. The boy was in critical condition with low cardiac output. The left ventricular end-diastolic volume was calculated as $62 \%$ of normal, whereas that of the right ventricle was $378 \%$ of normal according to the biplane Chapman method (Figure 1). The pulmonary/systemic pressure ratio, pulmonary resistance, and pulmonary artery index were $0.21,2.63 \mathrm{U} \cdot \mathrm{m}^{2}$, and 268 , respectively. Therefore, we concluded that the combination of the bidirectional Glenn shunt with interatrial fenestration and partial right ventriculectomy was the ideal surgical option.

From the Departments of Surgery ${ }^{\mathrm{a}}$ and Pediatrics, ${ }^{\mathrm{b}}$ Yamanashi Medical University, Yamanashi, Japan.

Received for publication March 12, 2001; accepted for publication April 6, 2001.

Address for reprints: Shinpei Yoshii, MD, Yamanashi Medical University, Tamaho-cho, Nakakoma-gun, Yamanashi, 409-3898, Japan (E-mail: syoshii@ res.yamanashi-med.ac.jp).

J Thorac Cardiovasc Surg 2001;122:1026-8

Copyright $\odot 2001$ by The American Association for Thoracic Surgery

0022-5223/2001 \$35.00+ $0 \quad \mathbf{1 2 / 5 4 / 1 1 6 3 1 9}$

doi:10.1067/mtc.2001.116319
The operation was performed when the patient was 9 months old and weighed $7.6 \mathrm{~kg}$. Cardiopulmonary bypass was instituted with the aid of transesophageal echocardiographic monitoring. When the beating right atrium was opened, massive tricuspid regurgitation was visible. The regurgitation was mainly due to prolapse of the anterior leaflet. Next, the free wall of the right ventricle was incised and inspected. It was extremely thin, suggesting fibrous change within the white inner surface. The free wall was almost entirely resected in a triangular fashion, but the anchoring portion of the anterior papillary muscle was left connected. The root of the anterior papillary muscle was transferred to the apex and reimplanted with 5-0 nonabsorbable monofilament sutures. The right ventricle was sutured from each end of the incision (Figure 2). A water test of the tricuspid valve showed a good result with only mild residual regurgitation. The fenestration, $4 \mathrm{~mm}$ in diameter, was created on the atrial septum, and then the atrial wall was slightly plicated and repaired. The superior vena cava was divided and anastomosed to the side of the right pulmonary artery in the ordinary fashion. Bypass was discontinued and modified ultrafiltration was used to stabilize hemodynamics.

The patient was weaned from mechanical ventilation on the day of the operation and had an uneventful postoperative course. Repeated measurement on echocardiography revealed that the dimension of the left ventricle had increased immediately, and the ventricle was restored to the expected normal size in 3 days. No arrhythmias were noted. The patient was discharged from the hospital in stable condition 4 weeks after the operation. A rightto-left shunt was visible on the transesophageal echocardiogram intraoperatively, which became bidirectional 1 month after discharge. Five months after the operation, an angiogram was done in which shunt flow could not be detected, and the left ventricular end-diastolic volume had increased to $98 \%$ of normal.

\section{Comment}

$\mathrm{Uhl}^{1}$ first reported a case of almost total absence of the myocardium of the right ventricle in 1952. This anomaly is rare, and when the symptoms appear during infancy, death is almost universal. ${ }^{2}$

No curative surgical procedure has been described for this anomaly. Kreutzer and associates ${ }^{3}$ have reported using the one and a half ventricle repair in hypoplastic right heart cases, and among them there was only 1 case of Uhl anomaly. Mavroudis and colleagues ${ }^{4}$ also documented 1 case of Uhl anomaly in their report of bidirectional Glenn shunt and one and a half ventricle repair. However, details have not been reported in either case and partial right ventriculectomy was not done. 


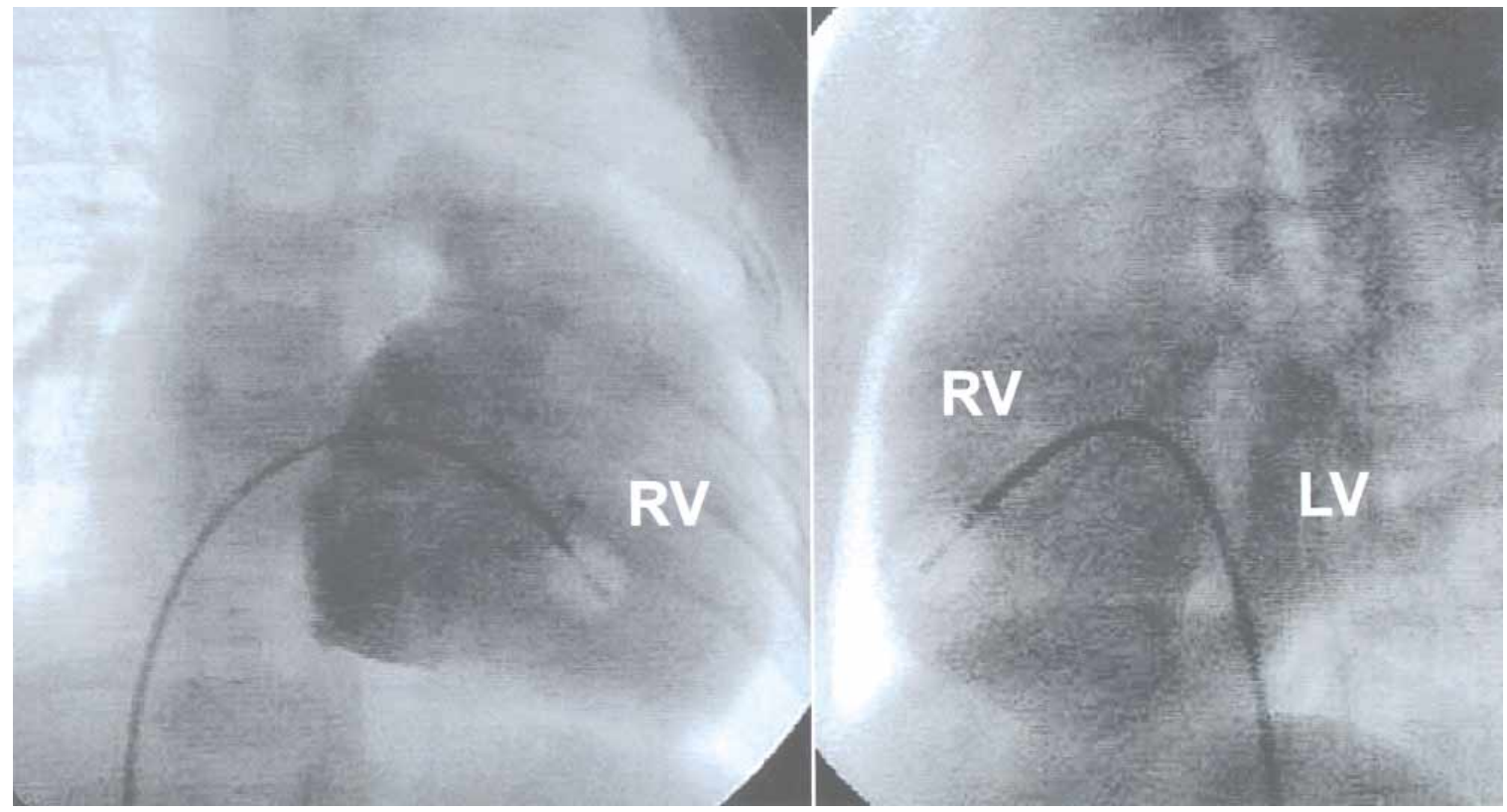

Figure 1. The left ventricular end-diastolic volume was $62 \%$ of normal, whereas the right ventricular end-diastolic volume was $378 \%$ of normal. $R V$, Right ventricle; $L V$, left ventricle.
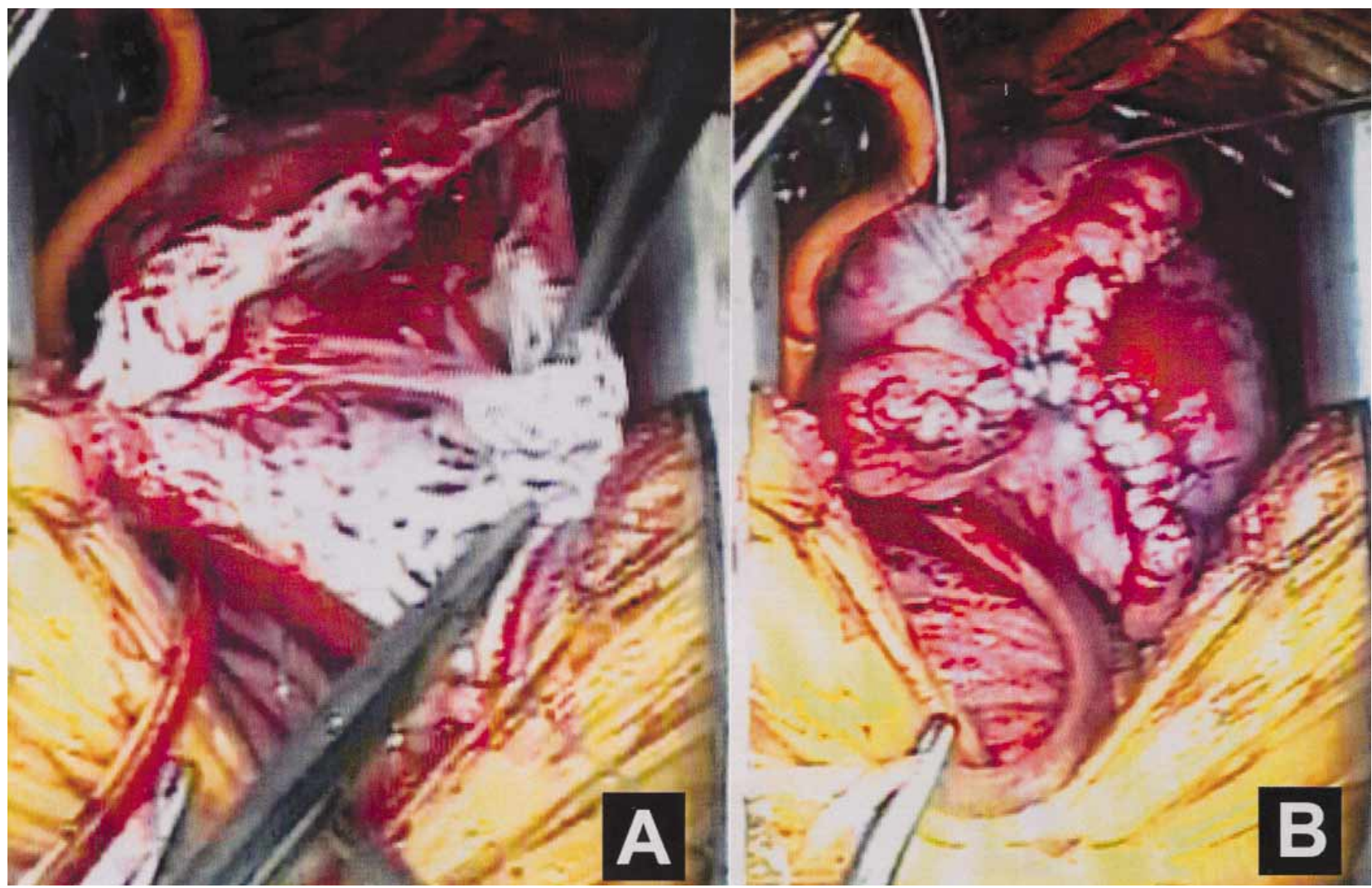

Figure 2. Almost the entire free wall was resected triangularly except for the anchoring position of the anterior papillary muscle (A). The root of anterior papillary muscle was transferred to the apex of the right ventricle. Then the right ventricle was closed from 3 corners (B). 
When surgical treatment for this anomaly is being considered, several questions arise: (1) Does the left ventricle have the volumetric and functional capacity to support the systemic circulation? (2) Does the situation warrant a one and a half ventricle repair? (3) How should the volume of the right ventricle be reduced? (4) Is it necessary to create a fenestration? Another concern is the occurrence of arrhythmias in the long term.

We believe that the shape of the left ventricle adapts quickly to new volume and pressure demands after the procedure. We are satisfied with the procedure and with the reduction in right ventricular volume. The remaining right ventricle returns venous blood from the inferior vena cava to the pulmonary artery assisted by left ventricular contraction. When the total cavopulmonary connection is done without volume reduction of the right ventricle, we speculate that there is no room to allow adequate filling and contraction of the left ventricle. This is the first report of partial right ventriculectomy and a one and a half ventricle repair used successfully to treat an infant with Uhl anomaly.

\section{References}

1. Uhl HSM. A previously undescribed congenital malformation of the heart: almost total absence of the myocardium of the right ventricle. Bull Johns Hopkins Hosp. 1952;91:197-209.

2. Uhl HSM. Uhl's anomaly revisited. Circulation. 1996;93:1483-4.

3. Kreutzer C, Mayorquim RdC, Kreutzer GOA, Conejeros W, Roman MI, Vazquez H, et al. Experience with one and a half ventricle repair. J Thorac Cardiovasc Surg. 1999;117:662-8.

4. Mavroudis C, Backer CL, Kohr LM, Deal BJ, Stinios J, Muster AJ, et al. Bidirectional Glenn shunt in association with congenital heart repairs: the 11/2 ventricular repair. Ann Thorac Surg. 1999;68:976-82. 